\title{
BMJ Open How much could a low COVID-19 pandemic change the injury trends? A single-institute, retrospective cohort study
}

\author{
Ling-Wei Kuo (1) , Chih-Yuan Fu, Chien-An Liao, Chien-Hung Liao, Yu-Tung Wu, \\ Jen-Fu Huang, Chi-Hsun Hsieh, Chi-Tung Cheng
}

To cite: Kuo L-W, Fu C-Y, Liao C-A, et al. How much could a low COVID-19 pandemic change the injury trends? A single-institute, retrospective cohort study. BMJ Open 2021;11:e046405. doi:10.1136/ bmjopen-2020-046405

- Prepublication history and additional materials for this paper is available online. To view these files, please visit the journal online (http://dx.doi org/10.1136/bmjopen-2020 046405).

Received 28 0ctober 2020 Revised 04 February 2021 Accepted 10 February 2021

Check for updates

(c) Author(s) (or their employer(s)) 2021. Re-use permitted under CC BY-NC. No commercial re-use. See rights and permissions. Published by BMJ.

Trauma and Critical Care Center, Chang Gung Memorial Hospital Linkou Main Branch, Taoyuan, Taiwan

Correspondence to Dr Chi-Tung Cheng; atong89130@gmail.com

\section{ABSTRACT}

Objectives COVID-19 has changed the epidemiology of trauma. However, Taiwan is a country with a low COVID-19 threat, and people's daily lives have remained mostly unchanged during this period. The purpose of this study is to investigate whether the trend of trauma incidence and the service of trauma care is affected by the relatively minor COVID-19 pandemic in Taiwan.

Design A single-institute, retrograde cohort study. Setting An observational study based on the trauma registry of Chang Gung Memorial Hospital (CGMH).

Participants Trauma patients presented to the emergency department of CGMH in the period of 1 January to 30 June 2020 (week 1 to week 26) were designated as the COVID-19 group, with 1980 patients in total. Patients of the same period in 2015-2019 were designated as the pre-COVID-19 group, with 10334 patients overall.

Primary and secondary outcome measures The primary outcome is the incidence of trauma admission. Differences in trauma mechanism, severity, location and outcome were also compared in both groups.

Results A decrease in trauma incidence during March and April 2020 was noticed. Significant change $(p<0.001)$ in trauma mechanisms was discovered, with decreased burn (5.8\% vs $3.6 \%)$ and assault (4.8\% vs $1.2 \%)$, and increased transport accidents $(43.2 \%$ vs $47.2 \%)$ and suicide $(0.2 \%$ vs $1.0 \%$ in the COVID-19 cohort. A shift in injury locations was also found with a $5 \%$ decrement of workplace injuries (19.8\% vs $14.8 \%, p<0.001)$.

Conclusion The limited COVID-19 outbreak in Taiwan has led to a decreased incidence of trauma patients, and the reduction is mostly attributed to the decline in workplace injuries.

\section{INTRODUCTION}

COVID-19 is a highly infectious and potentially deadly pathogen. Since the first case being reported in Wuhan, China, on 31 December $2019,{ }^{1}$ the disease has rapidly become a global pandemic. ${ }^{2}$ During the disease's flooding spread, the medical care systems in the epicentres of the pandemic have made significant changes to adapt to the overwhelming demand for medical resources. ${ }^{3-5}$ When the influx of patients exceeded the surge capacity of the medical

\section{Strengths and limitations of this study}

This is the first study to discuss the relationship between the COVID-19 pandemic and Taiwan's injury trends.

- As most countries in the world are under severe COVID-19 outbreaks, this is one of the few studies describing how a low-volume pandemic could influence injury trends.

- The piecewise linear regression analysis in this study allows a visualised understanding of how the critical time points in the pandemic affected the trauma trends in Taiwan.

- The single-institute design of this study might not fully represent the nationwide pattern of trauma patients.

- Some of the socioeconomic factors from the open government database were not calculated weekly, so it could not correlate timely with the weekly variation of the pandemic and trauma trends.

care system, alteration in trauma care was also inevitable. ${ }^{6}$

Taiwan is a country with low COVID-19 threat, with only 452 confirmed cases (up to 16 July 2020) and no large-scale community transmission. ${ }^{7}$ Nevertheless, COVID-19 not only changed how medical systems handle trauma patients in the hospital end. Many articles have revealed that it also influenced the epidemiology of trauma in the patient end, ${ }^{8-10}$ with a reduction of injury incidences. Similar findings were also observed in countries with relatively fewer confirmed cases. ${ }^{1112}$ The purpose of this study is to investigate whether the trend of trauma incidence and the service of trauma care is affected by the relatively minor COVID-19 pandemic in Taiwan.

\section{MATERIALS AND METHODS}

This is a retrospective cohort study. Data were extracted from the trauma registry of Chang Gung Memorial Hospital (CGMH). 
CGMH is a level 1 trauma centre with 3700 beds, serving as a major trauma referral hospital for northern Taiwan. Trauma patients of all age groups and injury severities who presented to the emergency department of CGMH in the period of 1 January to 31 June 2020 (week 1 to week 26) were included in this study as the COVID-19 group. Patients of the same period (week 1 to week 26) in 2015-2019 were designated as the pre-COVID-19 group, representing the baseline average. Total patient volume was processed in weekly and monthly manners, and the trends in the two groups were compared. After the total patient count was calculated, patient variables including age, sex, Injury Severity Score, injury locations, trauma mechanisms and mortalities of the two groups were compared and analysed, with missing data excluded from this stage of analysis. The categories of locations included: domicile, workplace, road, outdoor/leisure and others. The categories of mechanisms included: burn, high fall (from $>1 \mathrm{~m}$ ), low fall (from $<1 \mathrm{~m}$ ), suicide, assault and others. $\mathrm{X}^{2}$ test and Mann-Whitney $\mathrm{U}$ test were used for analysis where appropriate.

We used the scatter plot of the weekly percentage change between the COVID-19 cohort and the average of the pre-COVID-19 cohort to analyse the trend of trauma epidemiology. Change of overall patient counts and the subgroup counts of different injury locations and mechanisms was visualised in this manner. We then undertook piecewise linear regression analysis to assess the impact of critical changing points of the COVID-19 pandemic. Three knots were chosen: week 10 (the beginning of the surge), week 12 (the peak of the surge) and week 17 (the end of the surge), meaning there would be four time segments being analysed.

For indirect supporting evidence, open data from the government ministries, including data from the National Fire Agency, Ministry of Transportation and
Communications, National Police Agency (NPA), Directorate General of Budget, Accounting and Statistics and Taiwan Stock Exchange, were also extracted to establish the relationship between clinical shifts and socioeconomic factors.

All data were analysed by Excel and R language.

\section{Patient and public involvement}

Due to the retrospective and database-based nature of this study, patients and the public were not involved.

\section{RESULTS}

In this study, 12314 patients were identified from the CGMH registry, with 10334 patients from the preCOVID-19 cohort (2015-2019) and 1980 patients from the COVID-19 cohort (2020). On chronological patient distribution, an obvious downfall of patient numbers in week 10 to week 17 (March and April) was seen in the COVID-19 cohort. In contrast, the distribution of patients was principally even between months in the preCOVID-19 era. This change in distribution was statistically significant $(p<0.001)$. When we stratified the cases weekly and compared with the COVID-19 pandemic in Taiwan, the trough of our trauma patient numbers was precisely matched to the time when the COVID-19 case number reached the peak (figure 1).

After the analysis of trauma volume distribution, patients with missing data were excluded from further analysis. Twenty-five patients from the COVID-19 cohort and 2096 patients from the pre-COVID-19 cohort were eliminated, and a total of 10203 patients entered the analysis for trauma characteristics. The mean age, sex distribution, injury severity and mortality were statistically similar between the two groups. Significant change $(p<0.001)$ in the distribution of mechanism was discovered, with

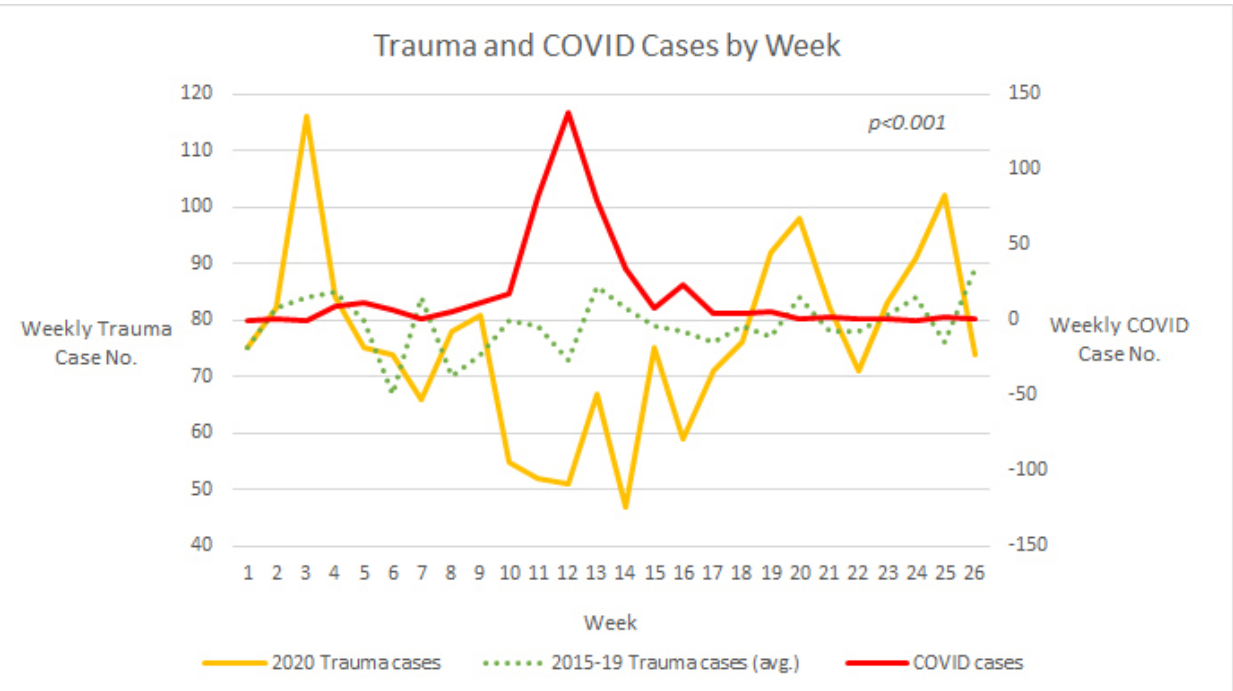

Figure 1 Weekly trend of trauma patient numbers in the COVID-19 era and pre-COVID-19 era and confirmed numbers of patients with COVID-19 in Taiwan. The yellow line represents the weekly trauma patient number in the COVID-19 era, and the green dot line represents the weekly trauma patient number in the pre-COVID-19 era. The red line is the weekly COVID-19 confirmed cases. 
Table 1 Basic demographics of the COVID-19 and preCOVID-19 cohorts

\begin{tabular}{|c|c|c|c|}
\hline \multirow[b]{2}{*}{ Variables } & \multicolumn{2}{|c|}{ All patients $(n=10203)$} & \multirow[b]{2}{*}{ P value } \\
\hline & $\begin{array}{l}\text { COVID-19 } \\
(n=1955)\end{array}$ & $\begin{array}{l}\text { Pre-COVID-19 } \\
(\mathrm{n}=8248)\end{array}$ & \\
\hline Age & $50 \pm 22.93$ & $49 \pm 23.44$ & 0.171 \\
\hline Sex & & & 0.613 \\
\hline Female & $744(38.1 \%)$ & $3088(37.4 \%)$ & \\
\hline Male & $1211(61.9 \%)$ & $5160(62.6 \%)$ & \\
\hline Mechanism & & & $<0.001$ \\
\hline Burn & $70(3.6 \%)$ & $480(5.8 \%)$ & \\
\hline High fall & $124(6.3 \%)$ & $645(7.8 \%)$ & \\
\hline Low fall & $560(28.6 \%)$ & $2276(27.6 \%)$ & \\
\hline Assault & $23(1.2 \%)$ & $398(4.8 \%)$ & \\
\hline Suicide & $19(1.0 \%)$ & $19(0.2 \%)$ & \\
\hline Transport & $923(47.2 \%)$ & $3563(43.2 \%)$ & \\
\hline Others & $236(12.1 \%)$ & 867 (10.5\%) & \\
\hline Injury location & & & $<0.001$ \\
\hline Domicile & $561(28.7 \%)$ & 2095 (25.4\%) & \\
\hline Workplace & $289(14.8 \%)$ & $1637(19.8 \%)$ & \\
\hline Road & 1009 (51.6\%) & 4080 (49.5\%) & \\
\hline $\begin{array}{l}\text { Outdoor/ } \\
\text { leisure }\end{array}$ & $44(2.3 \%)$ & $266(3.2 \%)$ & \\
\hline Others & $52(2.7 \%)$ & $170(2.1 \%)$ & \\
\hline Severity & & & 0.634 \\
\hline Major & $493(25.2 \%)$ & $2123(25.7 \%)$ & \\
\hline Minor & $1462(74.8 \%)$ & $6125(74.3 \%)$ & \\
\hline Outcome & & & 0.465 \\
\hline Survival & $1879(96.1 \%)$ & $7897(95.7 \%)$ & \\
\hline Mortality & $76(3.9 \%)$ & $351(4.3 \%)$ & \\
\hline
\end{tabular}

${ }^{*}$ COVID-19=2020, pre-COVID-19=2015-2019. COVID-19 stands for coronavirus disease 2019. decreased burn (5.8\% vs 3.6\%) and suicide/assault $(5.1 \%$ vs $2.1 \%)$, and increased transport accidents $(43.2 \%$ vs $47.2 \%$ ) in the COVID-19 cohort (table 1). A shift in injury locations was also found (figure 2), with a $5 \%$ decrement of workplace injuries $(19.8 \%$ vs $14.8 \%, \mathrm{p}<0.001)$.

The weekly trend assessment by piecewise linear regression revealed that there was a significant change in the overall trauma patient number $(\mathrm{p}=0.049$, see online supplemental table), with a sharp fall after week 10, reaching the bottom at week 12 and returned to a slight increase of patient volume after week 17 (figure 3A). In the subgroup analysis for injury locations, a gradually increasing domicile injury (figure $3 \mathrm{~B}$ ) was observed after week 10 with statistical significance $(\mathrm{p}=0.004$, see online supplemental table). A similar trend can also be observed in the proportion of low-height fall mechanism (figure 3C), which is often associated with residential injuries. ${ }^{13} 14$ No statistical significance could be reached on the trend of workplace injuries. However, there was a unanimous decrement during the pandemic surge on the scatter plot for the weekly percentage change of workplace injuries. In contrast, the trend before and after the surge showed high variation (figure 3D). Trends in road injuries (figure 3E) and transportation mechanism (figure 3F) were very similar. A downfall started at week 10, reaching the bottom at week 12 and then gradually returning to the plateau after the pandemic surge. However, both trends were not statistically significant. Other injury locations and mechanisms sharing for less than $10 \%$ of the total patient numbers did not enter the piecewise linear regression due to small sample sizes.

\section{DISCUSSION}

As a country with a low COVID-19 pandemic, the society and the medical system in Taiwan did not go through the overwhelming impact like other parts of the world.
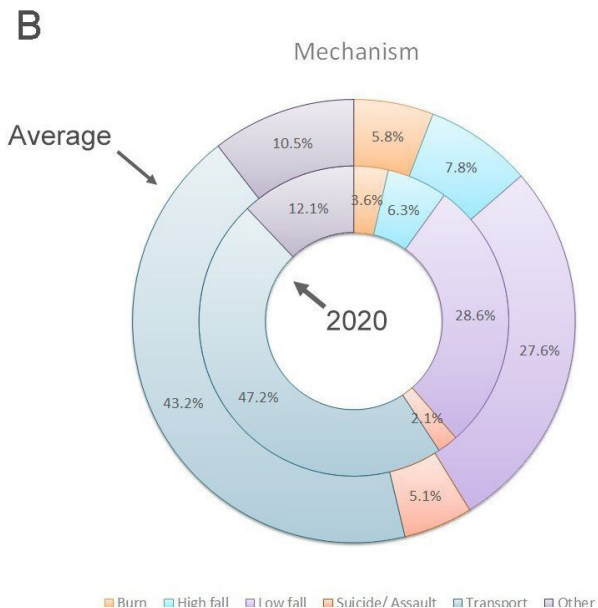

Figure 2 The comparison of injury locations (A) and mechanisms (B) between COVID-19 era and pre-COVID-19 era. The inside circle of the double pie chart represents the COVID-19 era, and the outer circle represents the pre-COVID-19 era. The subgroup of suicide injuries was combined to the assault injury subgroup in this graphic presentation due to its small sample size. 
There was no massive influx of respiratory patients, and the government did not adopt a lockdown strategy. However, we did experience a decline in the number of trauma patients, as reported in many other countries. Kenanidis and Tsiridis reported a pattern of decreased trauma patients in the first month of lockdown, but made a bounce back in the second month in Greece. ${ }^{15}$ They attributed this trend to the assumption that people became familiar with the restrictive measures. However, the scenario in Taiwan was quite different, since the only restrictive manners that the government applied to people were wearing a mask in public and social distancing.

In this study, we used piecewise linear regression analysis to assess the influence of each critical point during the pandemic, which was similar to the article published by Mulholland et al, describing the impact of COVID-19 on different hospital admissions in Scotland. ${ }^{16}$ Although the extent of COVID-19 threats was different between the two countries, we were still able to identify how the pandemic has reshaped the trauma epidemiology in Taiwan by lessening workplace injuries and increasing domicile injuries.

In our theory, the curve of the trauma patients was more likely to be due to the decline of economic activities under the COVID-19 pandemic. In figure 4, we can identify that the pandemic started to heat up at week 10 of 2020 , reaching the pinnacle at week 12 and gradually reduced to a low point at week 17. Interestingly, the Taiwan stock market also followed the same pattern, entering the lowest point at week 12. It is also at week 12 that our trauma patient number reached the nadir. Despite having a real COVID-19 outbreak, under the fear of an anticipating pandemic, people tended to decrease economic activities, and the incidence of trauma declined as a result. A recession of the proportion of workplace injury in our patients is compatible with our assumption. On the monthly open data, there is also a decline of the daily highway million vehicle/kilometres, which represents the traffic flow, and the daily rescue mission of the emergency medical technician. Although not counted weekly, these numbers' decrement grossly matched the previously mentioned pattern of COVID-trauma interaction, which provided some indirect evidence of our theory.

Interaction between economic performance and health status is not a new concept. Ruhm has proposed a theory that economic recession might actually be good for human health, stating that economic boost would lead to engaging high-risk behaviours to health. ${ }^{17}$ Several
A

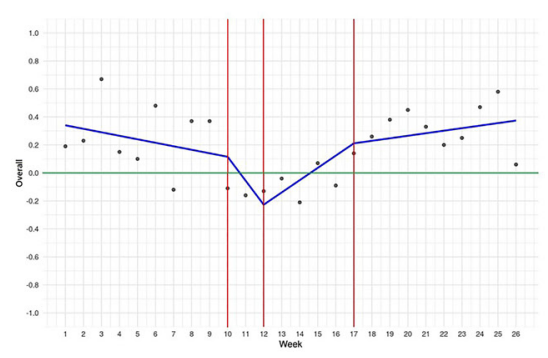

D

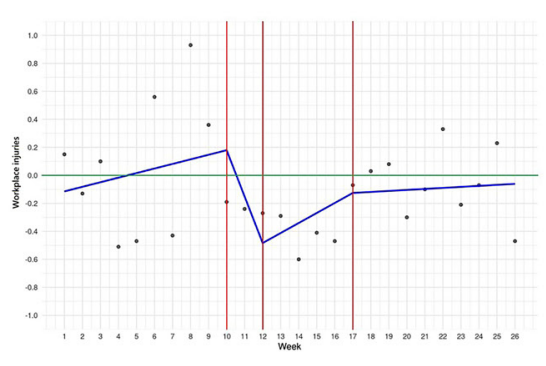

B

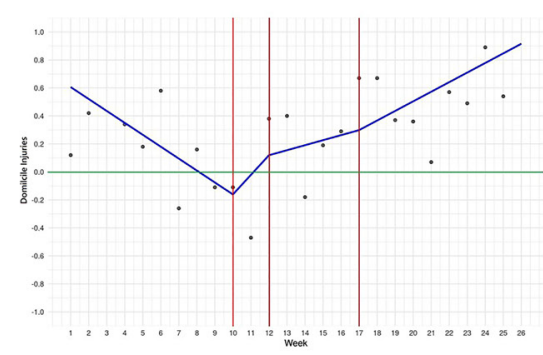

E

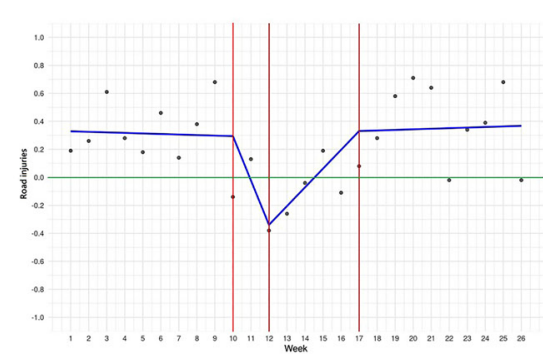

C

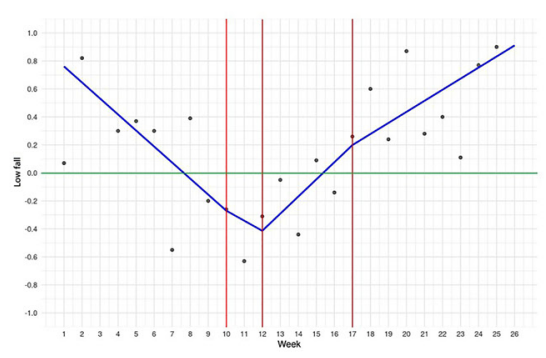

F

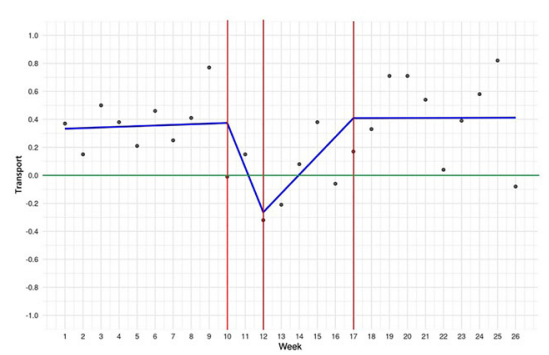

Figure 3 The scatter plot of the weekly percentage change of trauma patient volume between the COVID-19 cohort and the average of pre-COVID-19 cohort, and the piecewise linear regression model. The grey dots represent the percentage change in each week, presented in ratio manner in the $y$-axis $(1.0=100 \%,-1.0=-100 \%)$. The blue line represents the piecewise linear regression model. The three red lines at the $\mathrm{x}$-axis represent the three knots (week 10, week 12 and week 17) in the analysis. The green line at the $y$-axis signifies the baseline ( $0 \%$ change). (A) The model of overall trauma patients. (B) The model of injury by low-height mechanism subgroup. (C) The model of injury by transportation mechanism subgroup. (D) The model of injury in domicile location subgroup. (E) The model of injury in workplace location subgroup. (F) The model of injury in road location subgroup. 


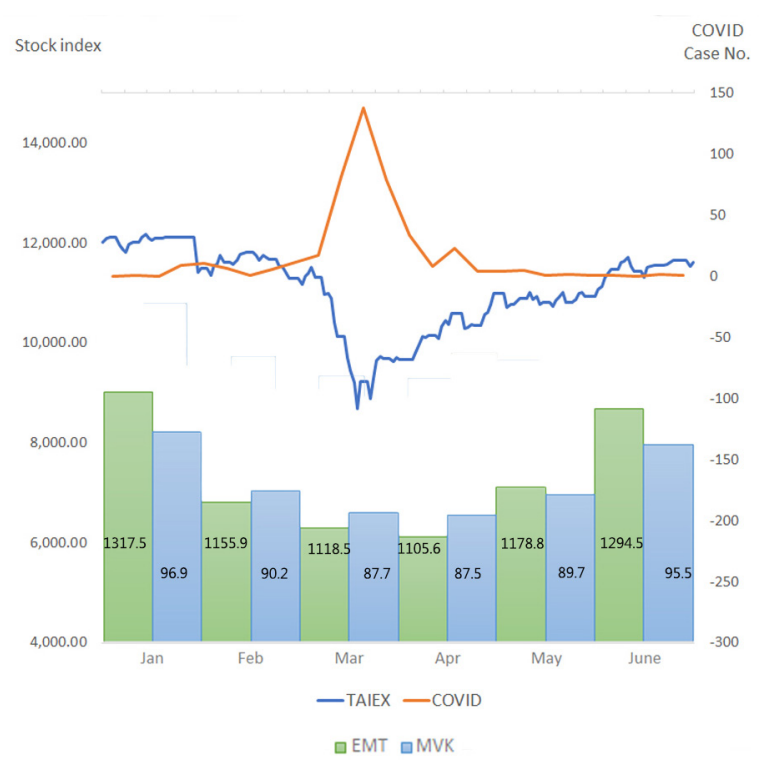

Figure 4 The relationship between COVID-19 case number and economic activities in Taiwan. At the upper half of the figure, the orange line (COVID) represents the confirmed COVID-19 case numbers, and the blue line (TAIEX, Taiwan Stock Exchange Capitalization Weighted Stock Index) represents the Taiwan stock index. At the bottom half of the figure, the green bar represents the monthly data of average daily rescue mission by the emergency medical technician (EMT), and the blue bar represents the monthly data of average daily traffic flow, presented by highway million vehicle/kilometres (MVK).

articles have also reported that workplace injury is positively related to economic growth ${ }^{18-20}$ which is compatible with our findings. The shift in injury mechanism in our cohort can provide further backup for our hypothesis, with decreased burns and high falls, which are often associated with workplace injuries. ${ }^{21}{ }^{22}$ One might argue that the increase in road injury indicated more traffic activities, which contradicts our economic recession hypothesis. However, during the COVID-19 pandemic, the food delivery business has gained explosive growth in Taiwan. ${ }^{23}$ The majority of these delivery services were transported by scooters and motorcycles, which can be highly dangerous, and often lead to traffic accidents, ${ }^{24}$ which may cause increased road injuries.

The incidence of suicide and assault injuries is another issue worth mentioning. Despite the small sample size, the incidence of suicide behaviours increased dramatically in the COVID-19 cohort with 19 admissions, whereas there were only 19 suicide admissions in the past 5 years combined. The COVID-19 pandemic has been reported to have a substantial negative impact on psychological aspects to the general population and medical professionals. ${ }^{25}$ Also, financial factors such as unemployment would further deteriorate mental health, ${ }^{26}$ leading to a possible increase in suicide risk. These findings were compatible with our results. However, we do have to state that our study population did not include substanceassisted suicide manners. The admissions via other routes, that is, psychiatric outpatient clinics, were not included either. Therefore, our results might not represent the full population with suicidal behaviour.

Assault, on the other hand, may have conflicting influence from the COVID-19 pandemic. Boman and Gallupe published a recent study and indicated that the COVID-19 pandemic might have decreased overall crime rates, but serious crimes such as homicide and intimate partner violence may have either remained constant or increased.$^{27}$ Being a country with a low crime rate and being placed in level 1 travel advisory by the US Bureau of Consular Affairs, ${ }^{28}$ Taiwan might not apply to the conclusion drawn from this article. In this study, we observed a prominent drop in the injuries due to assault. However, there were no significant changes in crime rates, either felonies or misdemeanours, from NPA's open database in the study period. ${ }^{29}$ Further investigation is needed to disclose the real reason for such decrement of assaultrelated injuries. Nonetheless, the issue of suicide and assault is way too extensive for the scope of this singlecentre study. We could only speculate the possible explanation of our statistics from the aforementioned data, but not to jump to a firm conclusion.

The major limitation of this study is that this is a singleinstitute study, so the findings in our institute might not fully represent the nationwide pattern of trauma patients. The low $\mathrm{R}$ squared value of our piecewise linear regression reflected the shortcoming of the single-institute design of our study. We believe that if more hospitals were involved, the outcome of the regression analysis would bring out a better explanatory model. However, being the largest trauma referral hospital in northern Taiwan, we believe that our hospital's paradigm shift can still reflect a part of the fact, if not the whole truth. Another drawback is that the stock market might not be a precise index for general economic performance, but it is a good reflection of consumer confidence, ${ }^{30}$ which is an appropriate impression of Taiwan under the COVID-19 pandemic: no actual damage, but more expecting terror.

\section{CONCLUSION}

Despite having a real lockdown or significant outbreak, the COVID-19 pandemic in Taiwan has led to a decreased incidence of trauma patients, regardless of severity. Based on our analysis, the reduction is mostly attributed to the decline in workplace injuries. A further nationwide study should be conducted to disclose more definite conclusions.

Acknowledgements The authors thank CMRPG3K1131, Dr Shih-Ching Kang, the coordinator of CGMH trauma registry databank, and F-P Kuo, C-J Chen and H-F Tien, members of the CGMH trauma registry databank, for their contribution to the data collection portion of the research.

Contributors LWK and CTC conceived and designed the study. CYF was in charge of the data collection. CHL and YTW provided statistical analysis of the data and contributed to the tables and figures. LWK and CAL drafted the manuscript and critical discussion was made with CAL, JFH and CHH. CTC takes responsibility for the study as a whole, and all authors read and approved the final manuscript. 
Funding The authors have not declared a specific grant for this research from any funding agency in the public, commercial or not-for-profit sectors.

Competing interests None declared.

Patient consent for publication Not required.

Ethics approval In this study, we retrospectively review the trauma registry databank from our institute, and the study was approved by the Ethics Institutional Review Board of Chang Gung Medical Foundation under IRB number 202001261B0.

Provenance and peer review Not commissioned; externally peer reviewed.

Data availability statement Data are available upon reasonable request. This study was based on data from the trauma registry databank of Chang Gung Memorial Hospital. Clinical information and data are only available for review when approved by the Ethics Institutional Review Board of Chang Gung Medical Foundation.

Supplemental material This content has been supplied by the author(s). It has not been vetted by BMJ Publishing Group Limited (BMJ) and may not have been peer-reviewed. Any opinions or recommendations discussed are solely those of the author(s) and are not endorsed by BMJ. BMJ disclaims all liability and responsibility arising from any reliance placed on the content. Where the content includes any translated material, BMJ does not warrant the accuracy and reliability of the translations (including but not limited to local regulations, clinical guidelines, terminology, drug names and drug dosages), and is not responsible for any error and/or omissions arising from translation and adaptation or otherwise.

Open access This is an open access article distributed in accordance with the Creative Commons Attribution Non Commercial (CC BY-NC 4.0) license, which permits others to distribute, remix, adapt, build upon this work non-commercially, and license their derivative works on different terms, provided the original work is properly cited, appropriate credit is given, any changes made indicated, and the use is non-commercial. See: http://creativecommons.org/licenses/by-nc/4.0/.

ORCID iD

Ling-Wei Kuo http://orcid.org/0000-0001-6489-3723

\section{REFERENCES}

1 World Health Organization. Pneumonia of unknown cause - China, 2020.

2 Cucinotta D, Vanelli M. WHO declares COVID-19 a pandemic. Acta Biomed 2020;91:157-60.

3 Uppal A, Silvestri DM, Siegler M, et al. Critical care and emergency department response at the epicenter of the COVID-19 pandemic. Health Aff 2020;39:1443-9.

4 Litton E, Bucci T, Chavan S, et al. Surge capacity of intensive care units in case of acute increase in demand caused by COVID-19 in Australia. Med J Aust 2020;212:463-7.

5 Carenzo L, Costantini E, Greco M, et al. Hospital surge capacity in a tertiary emergency referral centre during the COVID-19 outbreak in Italy. Anaesthesia 2020;75:928-34.

6 Ross SW, Lauer CW, Miles WS, et al. Maximizing the calm before the storm: tiered surgical response plan for novel coronavirus (COVID-19). J Am Coll Surg 2020;230:1080-91.

7 Minister of Helath and Welfare, Taiwan. Timeline of COVID-19, 2020.

8 Hernigou J, Morel X, Callewier A. Staying home during "COVID-19" decreased fractures, but trauma did not quarantine in one hundred and twelve adults and twenty eight children and the "tsunami of recommendations" could not lockdown twelve elective operations. Int Orthop 2020.

9 Comelli I, Scioscioli F, Cervellin G. Impact of the COVID-19 epidemic on census, organization and activity of a large urban emergency department. Acta Biomed 2020;91:45-9.

10 Haffer H, Schömig F, Rickert M, et al. Impact of the COVID-19 pandemic on orthopaedic and trauma surgery in university hospitals in Germany: results of a nationwide survey. J Bone Joint Surg Am 2020;102:e78.

11 Him Wong JS, Chee Cheung KM. Impact of COVID-19 on orthopaedic and trauma service. J Bone Joint Surg 2020.

12 Christey G, Amey J, Campbell A, et al. Variation in volumes and characteristics of trauma patients admitted to a level one trauma centre during national level 4 lockdown for COVID-19 in New Zealand. N Z Med J 2020;133:81-8.

13 Lee H, Kim SH, Lee SC, et al. Severe injuries from Low-height falls in the elderly population. J Korean Med Sci 2018;33:e221.

14 Kool B, Ameratunga S, Hazell W, et al. Unintentional falls at home among young and middle-aged New Zealanders resulting in hospital admission or death: context and characteristics. N Z Med J 2010;123:75-84.

15 Kenanidis E, Tsiridis E. "Flattening the curve" of COVID-19 pandemic in orthopaedics and trauma: the Greek perspective. Injury 2020;51:1681-2.

16 Mulholland RH, Wood R, Stagg HR, et al. Impact of COVID-19 on accident and emergency attendances and emergency and planned hospital admissions in Scotland: an interrupted time-series analysis. $J$ R Soc Med 2020;113:444-53.

17 Ruhm CJ. Are recessions good for your health? Q J Econ 2000;115:617-50.

18 Asfaw A, Pana-Cryan R, Rosa R. The business cycle and the incidence of workplace injuries: evidence from the U.S.A. J Safety Res 2011;42:1-8.

19 Fernández-Muñiz B, Montes-Peón JM, Vázquez-Ordás CJ. Occupational accidents and the economic cycle in Spain 1994-2014. Safety Sci 2018;106:273-84.

20 Song L, He X, Li C. Longitudinal relationship between economic development and occupational accidents in China. Accid Anal Prev 2011;43:82-6.

21 Papp A, Haythornthwaite J. Ethnicity and etiology in burn trauma. J Burn Care Res 2014;35:e99-105.

22 Mao S-W, Liu X-J, Su C-P, et al. [Analysis of 574 cases of high-fall death]. Fa Yi Xue Za Zhi 2009;25:276-8.

23 Oung A. Food delivery skyrockets amid virus. Taipei Times 2020.

24 Everington K. 2 food delivery drivers die within 3 days, Taiwan govt. threatens fines. Taiwan News 2019.

25 Sher L. The impact of the COVID-19 pandemic on suicide rates. QJM: Monthly J Assoc Phys 2020.

26 Kawohl W, Nordt C. COVID-19, unemployment, and suicide. Lancet Psychiatry 2020;7:389-90.

27 Boman JHt, Gallupe O. Has COVID-19 changed crime? crime rates in the United States during the pandemic. Am J Crim Justice 2020:1-9.

28 Overseas Security Advisory Council Bureau of Diplomatic Security, U.S. Department of State. Taiwan 2020 Crime \& Safety Report, 2020.

29 National Police Agency, Ministry of the Interior, Taiwan. Criminal cases statistics, 2020.

30 Jansen WJ, Nahuis NJ. The stock market and consumer confidence: European evidence. Econ Lett 2003;79:89-98. 